\title{
Dining and Dying at Pompeii: Last Supper at Pompeii Exhibition Review
}

Isabelle Green, Shayni Solanki, Archie Green, Stephanie Young, Megan Woodberry, Oscar Fanti, Rhianna Pike and Georgia-May Brown, University of Warwick, Coventry

'This major exhibition will tell the story of the ancient Roman city of Pompeii's love affair with food and wine.' [https://www.ashmolean.org/pompeii]

When we think of Pompeii, our thoughts turn to the eruption of Vesuvius, but this exhibition showed that there was more to Pompeii than its destruction.

The first sight to confront a visitor to the exhibition was a statue of Bacchus, an expressive statue of the god of wine that created a striking first impression. It was presented in an eye-catching way, standing alone in the middle of a room, highlighted by the lighting, along with the painting of a banquet from the House of the Triclinium.

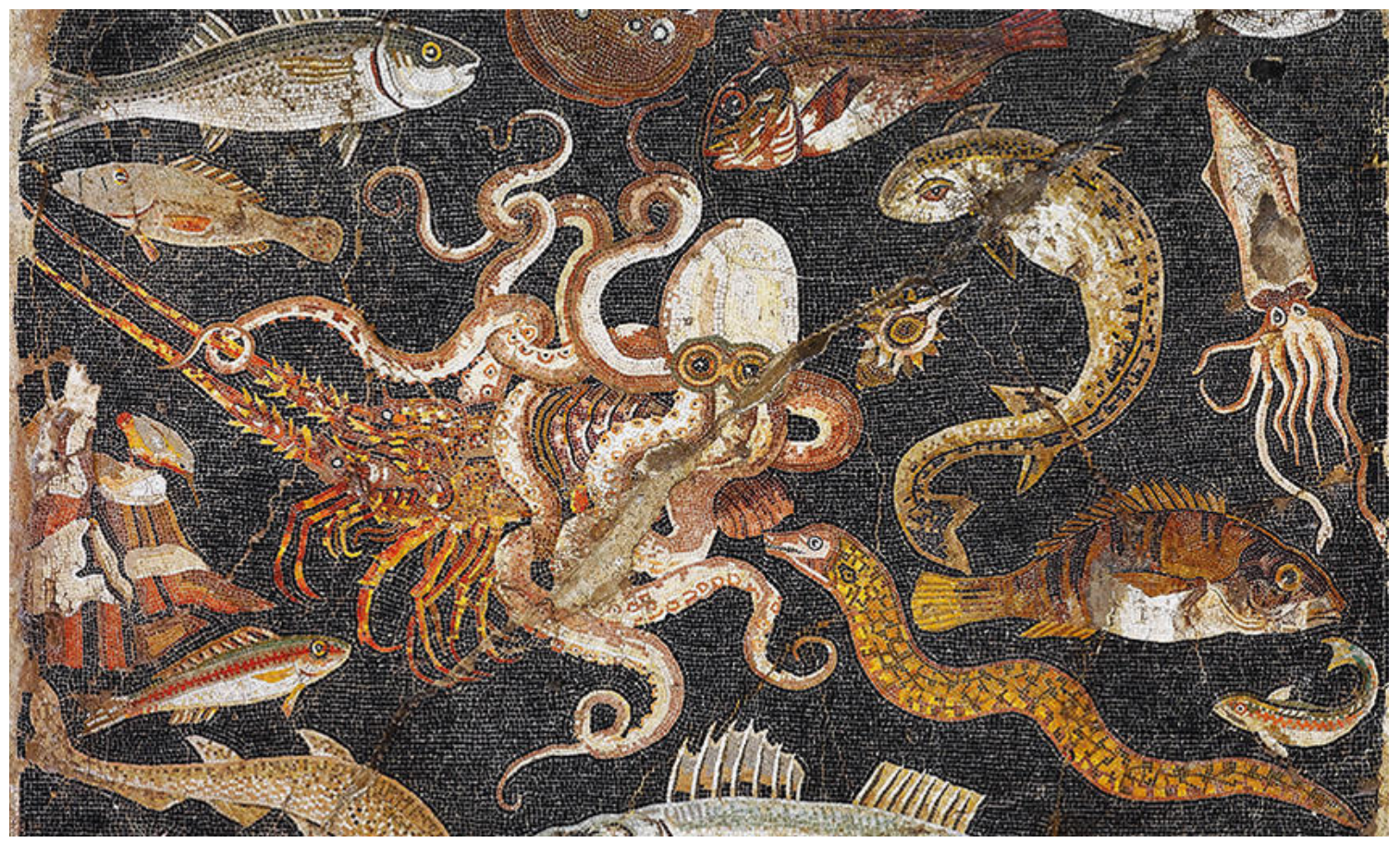

Figure 1: Fish Mosaic, Naples Museum, Inv. 120177

Fish and seafood were a common food source, as shown by the realism of this mosaic one of many that can be found on sites like Pompeii - on which even individual species can be identified. It displays some of the foodstuffs in which the Romans, particularly the wealthy, would indulge. In fact, the mosaic itself is a display of wealth 

- not only because it is fantastically designed but also because the display of sea produce shows that the owner of this mosaic clearly had money to spare.

Another interesting feature of the exhibition was the examples of carbonised food, including bread and pomegranate seeds, showing us what their diet may have been in the last few weeks of Pompeii. The display also indicated which foods were imported from other provinces or countries. The nearby display of pottery, glass and silverware showed the tools that families were using to cook and prepare their food, including a 'non-stick' frying pan. These everyday items made the people living in Pompeii feel more real, rather than something that is almost like a myth.

The interactive elements throughout the exhibition were rather effective, notably the 'Roman Master Chef' competition, where visitors were invited to write down a menu inspired by the exhibition. There was also an area dedicated to dining outside in a Roman garden, with typical sounds of a summer's day playing. This made the exhibition more immersive, helping create an impression of daily life as opposed to the usual view of Roman culture, which too often focuses upon political history alone.

The final element of the exhibition was the resin cast of the Lady of Oplontis, linking the theme of death with that of dining. This was a sombre ending; the nature of the figure made all the more striking by the dim, focused lighting. While it was impressive that the Lady of Oplontis was on display, she felt under-represented, as she was alone at the back of the exhibition and didn't seem relevant to the other items. Her jewellery was presented separately in a cabinet. This was emotionally provoking; in this cabinet was a string of beads historians think was given to her by a child, further highlighting that these people were ordinary citizens, just like us.

These remnants of Pompeii truly give a sense of being close to history, and bring us closer to comprehending and understanding the ancient world.

\section{List of Figures}

Figure 1: Fish Mosaic, Naples Museum, Inv. 120177

https://commons.wikimedia.org/wiki/File:Fish_Catalogue_MAN_Napoli_Inv120177 n02.jpg, accessed 28 November 2019 
Reinvention: an International Journal of Undergraduate Research 13:1 (2020)

To cite this paper please use the following details: Green, I., Solanki, S., Green, A., Young, S., Woodberry, M., Fanti, O., Pike, R \& Brown, G (2020), 'Dining and Dying at Pompeii: Last Supper at Pompeii Exhibition Review', Reinvention: an International Journal of Undergraduate Research, Volume 13, Issue 1, https://reinventionjournal.org/article/view/587. Date accessed [insert date]. If you cite this article or use it in any teaching or other related activities please let us know by emailing us at Reinventionjournal@warwick.ac.uk. 